\title{
Chlorofluorocarbons as Time- Dependent Tracers IN THE OCEAN
}

By John L. Bullister

$\mathrm{C}$

HLOROFLUOROCARBONS (CFCs) are al group of anthropogenic compounds which are widely used as refrigerants, aerosol propellants, plastic foam blowing agents and solvents. Although often popularly referred to by the Dupont tradename "freons," these compounds are produced worldwide by a number of manufacturers. CFCs have low toxicity. are not very reactive under normal conditions, and have a variety of useful physical properties. Production of two of these compounds, dichlorodifluoromethane (F-12) and trichlorofluoromethane (F-11), began in the early 1930s. Industrial production of $\mathrm{F}-11$ and $\mathrm{F}-12$ accelerated during the following three decades as demand for these compounds grew. CFCs are volatile, and most of the F- 11 and F- 12 produced eventually enters the atmosphere. In some applications, such as the use of F-1I and F-12 as aerosol propellants. the lypical delay between production and release of the CFC to the atmosphere is relatively short. but for other uses. such as in hermetically sealed refrigeration systems, the average delay until release can be a decade or longer.

Sensitive analytical techniques for measuring CFCs in the environment were not available during the first four decades of release. Pionecring measurements of CFCs in the troposphere were made by Lovelock (1971) using electron-capture gas chromotography. Since then, a number of programs have been established to monitor the increases of F-11 and F-12 in the earth's atmosphere as a function of location and time. For the period prior to the start of monitoring programs, the increase of CFCs in the atmosphere can be modeled based on production records and release scenarios. with corrections for losses due to photolysis of these compounds in the stratosphere.

More than $90 \%$ of production and release of F-11 and F-12 occurs in the Northern Hemisphere. Due to rapid mixing rates within the lower atmosphere, and the chemical stability of CFCs, the latitudinal distributions of these compounds in the earth's troposphere are relatively uniform. In 1987, the gradient between mid-latitude concentrations of these CFCs in the northern hemisphere and in remote regions in

John L. Bullister. Woods Hole Oceanographic Institution. Wood Hole. MA () 2543 . the Southem Hemisphere was only about $7 \%$.

Fig. 1 show's models of the increases of F-11 and F-12 in the troposphere over the Weddell Sea in Antarctica for the period 193(-1987. Data in this figure for the period 1976-1986 are based on a time series of measurements at the South Pole (Rasmussen and Khalil. 1986) and are normalized to 1987 measurements made in the Weddell Seal using the Scripps Insititution of Oceanography calibration scale (Bullister, 1984). For the period 1930-1975. estimates of accumulation of F-11 and F-12 in the atmosphere are based on annual production and release data (Chemical Manufacturers Association. 1985) with corrections applied for stratospheric removal processes. Both F-11 and F-12 have increased rapidly in the atmosphere from 1930 to the present. During the period 1930-1975, the ratio of F-11/F-12 in the atmosphere also increased monotonically as a function of time. Since the mid-1970s. the F-1 1/F-12 ratio in the atmosphere has remained about constant.

\section{Ozone Destruction}

Much of the interest in the accumulation of $\mathrm{CFC}$. in the atmosphere hals focused on their role in the destruction of stratospheric ozone. Due to their chemical inertness in the troposphere, these compounds are gradually carried upward into the stratosphere. where they undergo photolysis by high energy ultraviolet light. This photolytic process initiates a chain of reactions which result in the catalytic destruction of stratospheric ozone (Molina and Rowland, 1974). Intense public debate arose als the risks from reductions in the earth's ozone layer were weighed against the economic importance of CFCs. Concerns over possible danger to human health and the environment led to cnactment of restrictions on some uses of these compounds in the US in 1976. Nevertheless. worldwide use of CFCs has remained high during the past decade. Recently, much attention has been focused on studies which show that total column ozone levels over Antarctica in early spring have declined sharply during the past decade (Farman et al.. 1985). The observed decline of Antarctic ozone (the "Ozone Hole") is much greater than that predicted by earlier models of global stratospheric chemistry. and has sparked renewed concern over the environmental 


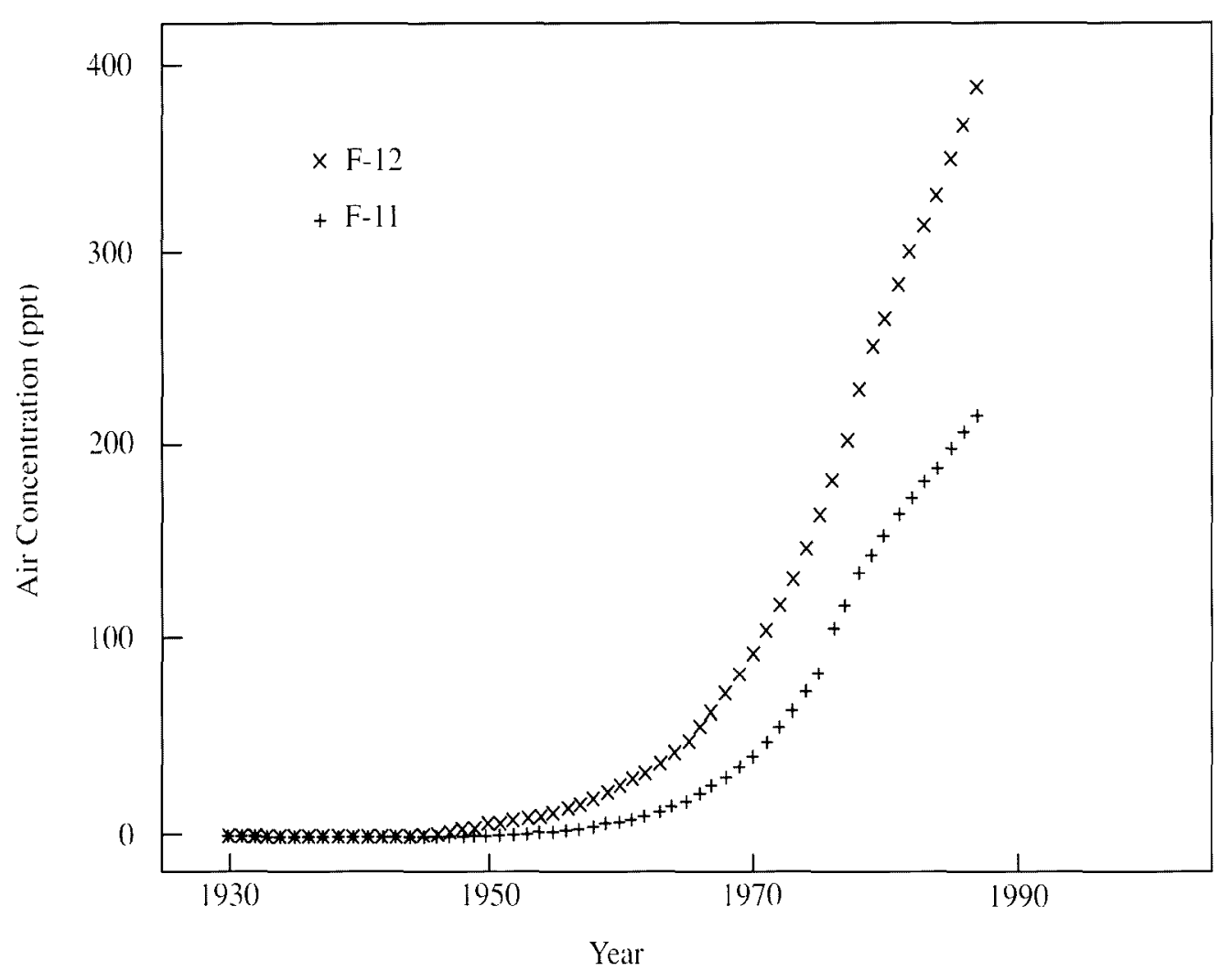

Fig. I: Trichlorofluoromethane (F-II) and dichlorodifluoromethane $(F-12)$ concentrations in the troposphere over Antarctica (ppt=parts per trillion). For the period 19.30-1975. this model is based on industrial production and release estimutes. From 1975-19,87, the model is based on a time-series of atmospheric measurements

effects of these compounds.

CFCs (along with other gases such as $\mathrm{CO}_{2} . \mathrm{CH}_{4}$. and $\mathrm{N}_{2} \mathrm{O}$ ) are also very efficient absorbers of infrared radiation, and increasing concentrations of CFCs in the atmosphere may make a substantial additional contribution to global warming due to rising levels of atmospheric $\mathrm{CO}_{2}$ (Ramanathan. 1988).

The proposed 1988 Montreal Protocol treaty attempts to freezc CFC production at 1986 levels for the next few years. then gradually cut production by $50 \%$ during the $1990 \mathrm{~s}$. Even at these lower production and release rates. atmospheric concentrations of $\mathrm{F}-11$ and $\mathrm{F}-12$ will continue to rise during this period. Proposals have been made recently for a complete ban on production of some CFCs (including F- 11 and F-12) within a decade. A variety of compounds with lower potential for ozone damage are now being tested as possible substitutes for CFCs. Even with the elimination of new CFC production, the very slow removal of these compounds from the atmosphere conly about 1 '" per year via stratospheric photolysis). and the continued gradual release of existing stockpiles (including CFCs held in refrigeration systems. plastic foams. etc.) insures that these compounds will remain in the atmosphere at relatively high levels for many hundreds of years.

\section{The Entry of CFCs into the Ocean}

At equilibrium, the concentration of a dissolved CFC in the surface ocean is a function of its concentration in the overlying atmospherc and of the salinity and temperature of the seawater. A global model of the equilibrium concentrations of F-11 and F-12 in the mixed layer of the ocean. as a function of latitude and time. can be derived using models of sea surface temperature and salinity and of the increases of F-11 and F-12 in the troposphere.

From the surface layer, these dissolved compounds can be mixed downward in the water column. Using models of CFC inpul functions, and measurements of the distribution of these dissolved compounds in the water column, information can be obtained on the rates at which the ocean can take up gases from the atmosphere, and on mixing and circulation within the interior of the ocean.

Techniques have been developed for measuring the concentrations of dissolved F-11 and F-12 in seawater. A 24-sample water column profile of the concentrations of dissolved F-11 and F-12 can be obtained on board ship within eight hours of the completing of a station. These rapid analytical techniques allow CFC distributions to be obtained along conductivity-temperature-depth sections with reso-

\section{These}

compounds will remain in the atmosphere at relatively high levels for many hundreds of years. 


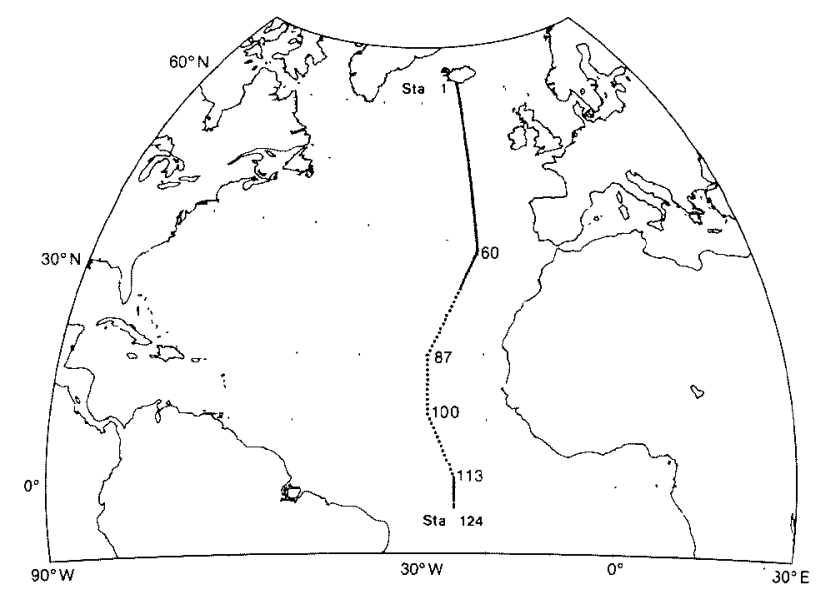

Fig. 2a: Dotted line indicates location of stations during 1988 North Atlantic CTD hydrographic study alomg approvimately $20^{\circ}$ West (Oceanus Cruise 202). Stations were occupied at about $1 / 2^{\circ}$ intervals along this meridional section. Water samples were collected and andyed for dissolved oxygen. nutrients. sulinity. 'HeTritium and CFCs.

lutions comparable to that for other chemical tracers, such as dissolved oxygen and nutrients. The limits of detection at present for F-11 and F-12 in small volume $\left(30 \mathrm{~cm}^{3}\right)$ seawater samples are better than $0.005 \times 10^{-12}$ mole $\mathrm{kg}^{-1}$ seawater (Bullister and Weiss. 1988). Typical modern near-surface concentration are about three orders of magnitude higher, allowing a wide dynamic range in the ocean for these tracers.

Additional modifications in sampling and analytical techniques may allow more rapid and automated processing of CFC samples. The continued transfer of CFCs from the surface layer into the interior of the ocean, together with improvements in the limits of detection for these compounds, will allow useful measurements of CFCs to be extended in the future to deeper and more isolated regions of the ocean.

The accurate determination of the concentrations of dissolved F-11 and F-12 in seawater is extremely susceptible to the entry of trace levels of contamination during sample collection and processing. CFCs can be present at very high levels in labotatory and shipboard air, and in almost all materials used in the walls and seals of sampling containers. Efforts are being taken to reduce such sample contamination, but this problem remains a major obstacle to the more routine determination of trace levels of dissolved CFCs in seawater.

A number of groups are involved in the study of the entry of CFCs into the ocean. Detailed vertical profiles of F-11 and F-12 in the North Pacific (Gammon et al. 1982) demonstrated the value of these compounds as time-dependent tracers in the upper ocean. CFCs have been used to study deep water formation rates in the Greenland-Norwegian Seas (Bullister and Weiss. 1983), the sub-surface transport of these compounds in the North Atlantic via deep western boundary currents (Weiss et al., 1985: Fine and Molinari, 1988), and the ventilation of the Arctic Ocean (Wallace et al., 1987; Smethie et al. 1988). The following discussion gives examples of two recent CFC studies.

\section{CFCs in the North Atlantic}

Sections of dissolved CFC concentrations were obtained on a cruise in the North Atlantic on the R/V Oceamus during July-Sept 1988. This section extended from Iceland to $3^{\circ} \mathrm{S}$ along about $20^{\circ} \mathrm{W}$ (Fig. 2a). About 2000 seawater samples were analyzed on board ship for F-12 and F-11 during this cruise. A section showing $\mathrm{F}-12$ concentrations is shown in Fig. 2b. Dissolved F-11 and F-12 concentrations in the near-surface layer along this summertime section were within a few percent of atmospheric equilibrium at most stations. Due to the strong dependence of F-1 1 and $F-12$ solubilities on temperature, highest concentrations of dissolved F-12 (and F-11) were found in the cold $\left(10-11^{\circ} \mathrm{C}\right.$ ) surface waters along the northern end of this section. The overflow of cold. dense water from north of the Iceland-Scotland Ridge system can be detected as a deep maximum $1>2000$ $\mathrm{m}$ ) in dissolved F-12 concentration at station 7-14. This overflow is an important component in the formation of North Atlantic Deep Water (NADW). Elevated levels of dissolved CFCs and other tracers carried in recently ventilated NADW (derived from combined overflow of dense waters formed to the north of the Greenland-Iceland-Scotland Ridge system ) can be traced in deep western boundary currents for thousands of kilometers southward in the western basin of the North Atlantic.

A sub-surface tongue of high-CFC water centered at a depth of about $1700 \mathrm{~m}$ extends southward along the section to about $40^{\circ} \mathrm{N}$. This maximum is associated with a relatively homogeneous, well-ventilated layer of cool. low salinity water formed in the region of the Labrador Sea. The sharp decrease in mid-depth F-12 concentrations south of about station 50 in Fig. $2 \mathrm{~b}$ is associated with the transition to a regime of warmer, saltier water more strongly influenced by outflow from the Mediterranean. 


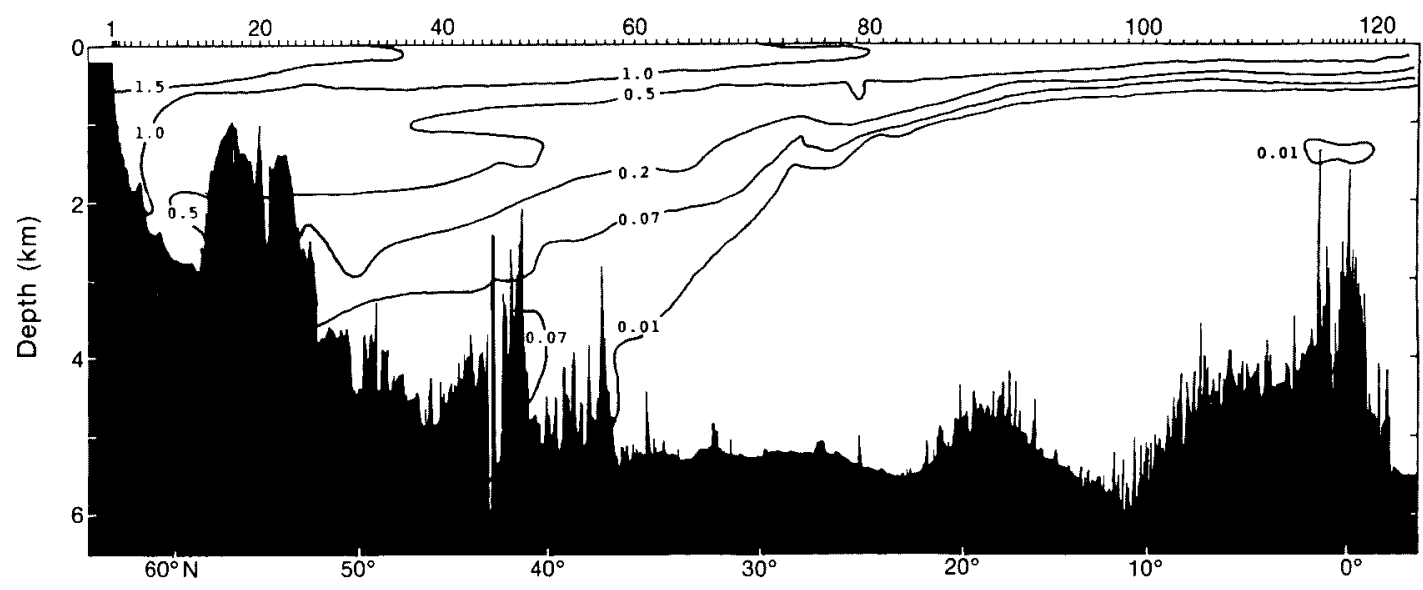

Fig. 2h: Dissolved F-12 (oncentrations (x 10-12 mole $\mathrm{kg}^{-1}$ ) along North Atlantic section. The limits of detection for F-12 are less than $0.005 \times 10^{12}$ mole $\mathrm{kg}^{-1}$. More than 2000 water samples were analyzed for CFCs along this section. Due to the relatively coarse contouring interyls used in this illustration, many details of the F-12 distribution ohserved along this section are not show'n. Samples were taken during Oceanus cruise 202.

At several stations along the cruise track. welldefined, anomously high temperature and salinity features were observed in the mid-depth water column. These features are thought to be parcels of relatively undiluted Mediterranean outflow water ("Meddies") which are transported rapidly from their formation region to this area. These features also contain elevated levels of dissolved CFCs relative to the background field. The deepening of the $0.5 \times$ $10^{-12}$ mole $\mathrm{kg}^{-1} \mathrm{~F}-12$ contour at station 79 (see Fig. 2b). for example, reflects the presence of a CFC maximun associated with the Meddy observed at this station. The rapid transport and decay of these short-lived features may have a significant role in determining the mean salinity, temperature and tracer fields in this region of the North Atlantic.

The concentrations of dissolved F-11 and F-12 are at or below detection limits in water deeper than about $500 \mathrm{~m}$ at stations south of about $20^{\circ} \mathrm{N}$. The ventilation of the mid-depth and deep waters of this region of the eastern North Atlantic are slow relative to time history of CFC release into the environment.

Of particular interest is the maximum in dissolved F-12 centered near the equator at a depth of about $1700 \mathrm{~m}$ (Fig. 2b). Earlier CFC studies during the Transient Tracers in the Ocean-Tropical Atlantic Study program detected the presence of mid-depth maxima in dissolved F-1 1 and F-12 extending along the equator from the western boundary near Brazil eastward toward the mid-Atlantic Ridge (Weiss ef al. 1985). The F-12 maximum shown in Fig. 2b is thought to represent the continuation of this deep, eastward equatorial transport to at least $25^{\circ} \mathrm{W}$ in the Atlantic.

\section{CFCs in the Southern Ocean}

Unlike a number of bomb-produced tracers which were deposited primarily in the Northern Hemisphere (e.g. tritium), the input functions for $\mathrm{F}-\mathrm{ll}$ and F-12 are similar for both northern and southern hemispheres. CFCs may be especially useful as trac- ers of ventilation of intermediate and deep waters in the Southern Ocean.

A study of dissolved F-1 1 and F-12 in Antarctica was made during the austral summer of 1987 on the West German R/V Polarstern. This study included detailed sampling on the shelf and slope region near the Filchner Ice Shelf in the southern Weddell Sea. and stations across the Weddell Gyre (Fig. 3a.p. 16).

Figures $3 b$ and $3 c$ (p.16) show dissolved F-11 concentrations and $F-11 / F-12$ ratios along a section crossing the Weddell Sea. The highest levels of dissolved F-11 and F-12 measured along this section were present in near-surface waters, and at ice-free stations were close to equilibrium with the overlying atmosphere. F-11/F-12 ratios were about 2.2 in nearsurface samples. and reflect the $\mathrm{F}-11 / \mathrm{F}-12$ ratio of modern air. Concentrations of dissolved CFCs decrease rapidly through the shallow $(100 \mathrm{~m})$ temperature minimum zone, which is a remnant from the base of acold, deep mixed layer which forms in this region in winter. Lower but non-zero concentrations of F-11 and $F-12$ are present throughout the deep waters along this section. F- 1 1/F- 2 ratios $<2$ in deeper waters are characteristic of atmospheric ratios prior to 1975. and reflect the isolation of this region from rapid atmospheric exchange.

The near bottom maximum in dissolved $F-12$ in Fig. $3 b$ is associated with the presence of a layer of cold. low-salinity new Weddell Sea Bottom Water (WSBW). The highest levels of dissolved CFCs $\left(>1.5 \times 10^{-12}\right.$ mole $\left.\mathrm{kg}^{-1}\right)$ in this layer were present in the the coldest WSBW banked along the western edge of the Weddell Sea near the tip of the Antarctic Peninsula (station 128 ). $\left.F_{-}\right] 1 / F_{-}-12$ ratios in the core of the WSBW are essentially modern and indicate the rapid transport (less than ten years) of surface derived waters into this region.

New WSBW is believed to be produced as the result of the outflow and mixing of cold. dense shelfderived waters with surrounding deep waters on the
CFCs may be especially useful as tracers of ventilation of intermediate and deep waters in the Southern Ocean. 


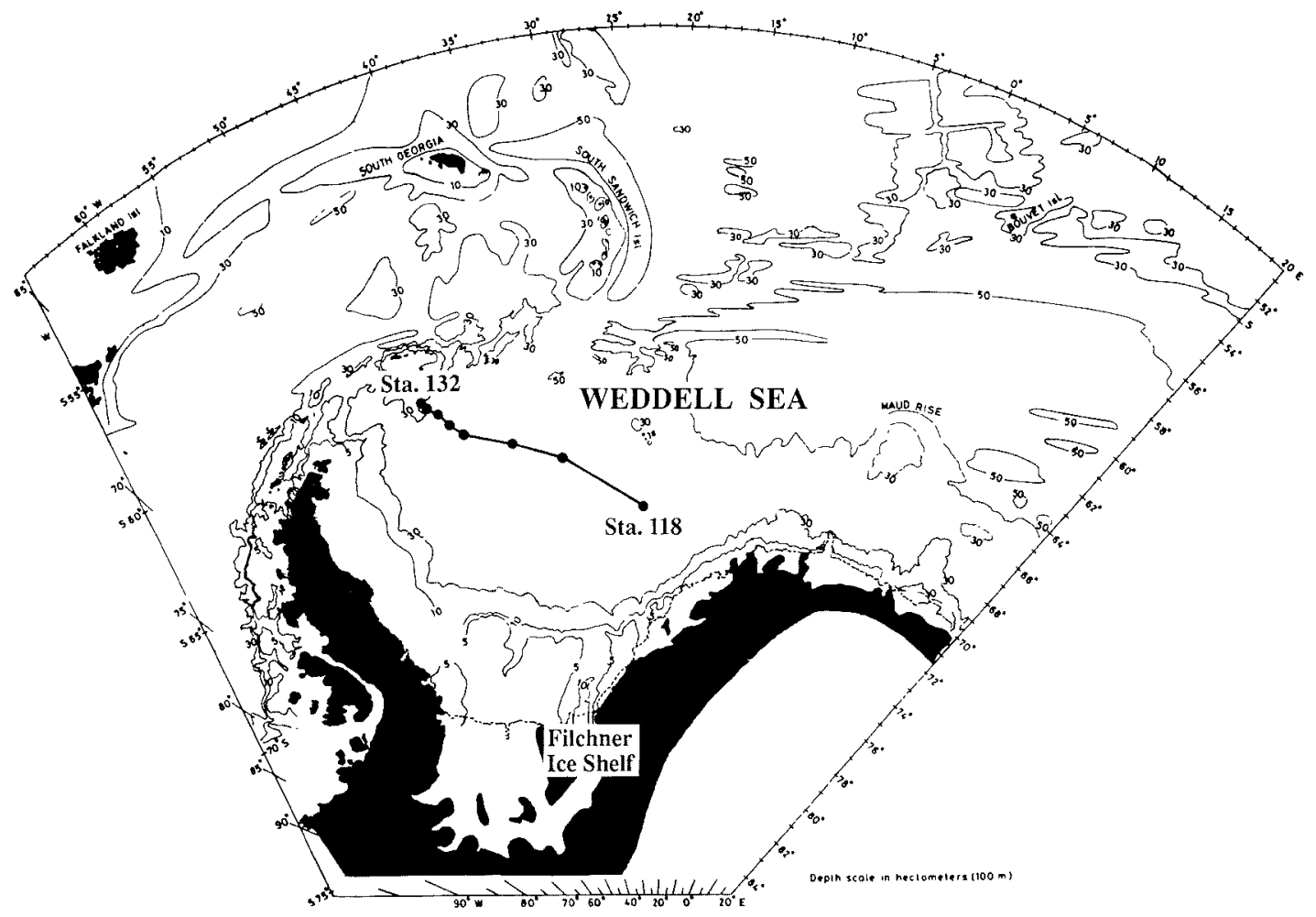

Fig 3a: Location of hydrographic Stations 118-1.32 during Weddell Sea study in 1987. The depth contours shown are in hectometers $(100 \mathrm{~m})$. New Weddell Sea Bottom Water (WSBW) containing high concentrations of dissolved CFCs is formed along the southern margins and transported through the deep Weddell Sea.

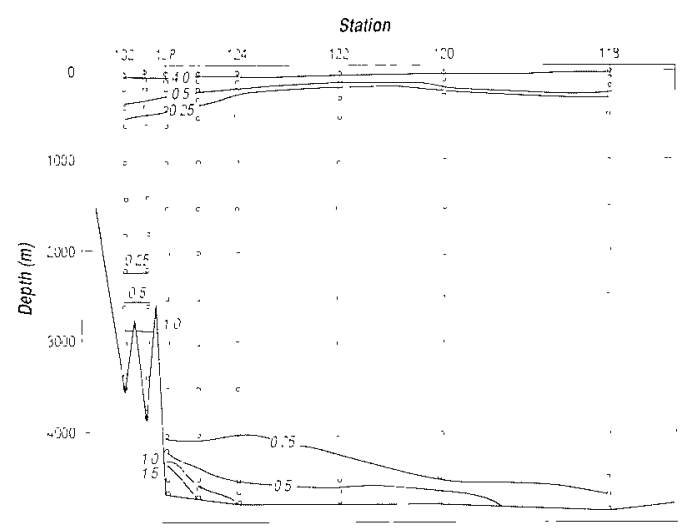

Fig. 3b: Dissolved F-II concentrations ( $10^{-12}$ mole $\mathrm{kg}^{-1}$ ) in a sertion crossing the Weddell Sea. Dots indicate locations where CFC samples nere collected. The flear hollom maximum in dissolved F-II is associated with a laver of WSBW. The highest levelsoldissolved F-11 in this laver found at station 28 near the base of the Antaritic Peninsula) are carried ina boundary carrent of icry cold new! formed $W S B W$.

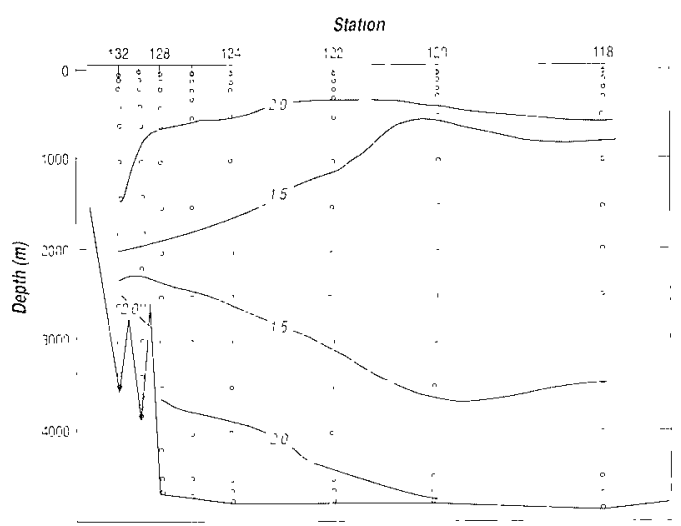

Fig. $30: F-11 / F-12$ ratio in the section crossing the Weddell Sea. Dissolved F-l//F-12 ratios $>2$ are characteristic of atmospheric ratios daring the past decade. Lower F-1 liF-12 ratios are characteristic of older. more slowly rentilated waters. 
continental slope north of the Filchner Ice Shelf. Dense varieties of shelf waters are produced by the rapid formation and export of sea ice in this region and by cooling of water circulating beneath the Filchner lce Shelf. Measurements made during the 1987 expedition show that. due to restricted air-sea exchange in this ice-covered region. CFC concentrations in these shelf waters are about $40 \%$ undersaturated relative to the overlying atmosphere. Mixing of these shelf waters with low CFC deep waters produce new WSBW, which at the time of its formation is significantly undersaturated in CFCs. Such information on the initial CFC content in new WSBW is needed to interpret the CFC signal present in WSBW and to estimate the rates of formation and transport of this water mass in the deep Weddell Sea.

\section{Future Studies}

A better understanding of boundary conditions for CFCs during water mass formation processes is essential to modeling distributions observed within the interior of the ocean. Although much of the surface ocean is in close equilibrium with the CFCs in the atmosphere, some processes (such as bottom water formation in Antarctica) involve components which are significantly undersaturated in dissolved F-11 and F-12. Studies are needed to determine the degrec of disequilibrium for CFCs in waters undergoing rapid deep convective mixing processes and the boundary conditions for CFCs during subduction of water along isopycnal surfaces into the interior of the ocean. In multi-tracer studies, a thorough understanding of the differences in boundary conditions for various time-dependent tracers, and the implications of these differences, will improve our ability to obtain quantitative information from the observed fields.

There are a number of other CFCs which maly prove useful as time-dependent ocean tracers. The concentration of $\mathrm{CCl}, \mathrm{FCClF},(\mathrm{F}-113)$ has been increasing very rapidly in the atmosphere during the past decade, and measurements of dissolved F-113 in seawater (Wisegarverand Gammon, 1988) may prove a valuable tool for studying processes occurring on this time scale. Halocarbons such as carbon tetrachloride and methyl chloroform. which have longer histories of release into the atmosphere than do the CFCs, may also prove to be valuable time-dependent tracers (Krysell and Wallace, 1988).

It is likely that dissolved CFC measurements will be included in the future along with more traditional tracer measurements (such as dissolved oxygen and nutrients) in many hydrographic programs. Together with other time-dependent tracers, such as ${ }^{2} \mathrm{He}$-tritium and ${ }^{1+} \mathrm{C}$. CFC studies will probably be an important component of global programs such as the World Ocean Circulation Experiment (WOCE). The Scientific Plan for WOCE (1988) includes in its goals the study of the existing and evolving tracer fields in the world ocean by means of a one-time global survey and selected repeat sections.

Large numerical models will incorporate the in- formation obtained by these global, multi-tracer studies to improve our understanding of the present rates and pathways of ocean circulation and mixing processes. and of the response of the ocean to changes in global climate.

\section{Acknowledgements}

I thank S. Doney. C. Johnston, R. Weiss and the crew and scientists on the R/V Oceanus and Polarstern for assistance with these studies. This work was supported by NSF Grants DPP-8619704 and OCE-8800957. This is WHOI Contribution Number 7092.

\section{References}

Bullister, J.L., 1984: Atmospheric Chlorofluorocarbon as Tracer of Ocean Circulation and Mixing: Measurement and Caltbration Techniques and Studies in the Greenland and Norwegian Seas. Ph.D. Thesis. Iniversity of California. San Diego, 172 pp.

Bullister. J.L. and R.F. Weiss, 1983: Anthropogenio Chlorofluorocarbons in the Greenland and Norwegian Seas. Seronce. 221. 265-268.

Bullister, I.L. and R.F. Weiss. 1988: Determination of CCl F and $\mathrm{CCl}, \mathrm{F}$ in seawater and air. Deep Sea Res.. 35/5),839-853.

Chemical Manulacturess Association, 1985: 1984 World production and sales of fluorocarbons $\mathrm{FC}-11$ and $\mathrm{FC}-12$. Chemical Manutacturers Release, Washington, D.C.

Farman. J.C.. B.B. Gardiner and J D. Shanklin. 1985: Large losses of totat ozone in Antarctica reveal seasonal $\mathrm{ClO} / \mathrm{NO}$ interacton. Nature, $315,207-210$.

Fine, R.A. and R.L. Molinari, 1988: A continuous deep westem boundary current between Abaco $(26.5 \mathrm{~N})$ and Barbados (13. N). De'es) Seates..35/9), 1+41-1+50).

Gammon, R.H.. J. Cline and D. Wisegarver. 1982: Chlorofluoromethanes in the Northeist Pacific Ocean: Measured vertical distibutions and Application as Transicnt Tracers of Lipper Occan Mixing.J. Genplswical

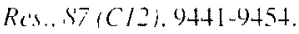

Loveloch.J.E. [97]: Atmosphenc fluorine compounds as indicators of ar movements. Nature 241.370 .

Krysell. M. and D.W.R. Wallace. 1988: Arctic Ocean Ventilation Studied with a suite of Anthropogenic Halocarbon Tracers. Sicince. 2t2. 746-748.

Molina. M.J. and F.S. Rowland, 1974. Stratospheric sink for chlorolluoromethanes: Chlorine atom catalysed destruction of orone. Neature. 249.810-812

Ramanathan, V., 1988: The Greenhouse Theory of Climate Change: A Test by an Inadvertent Global Experiment. Sicince. 2 \&0 $293-290$.

Rasmussen. R.A. and M.A.K. Khalil. 1986: Atmospheric Trace Gases: Trends and Distrobutions over the Last Decade. Sichere. 232, 1623-1624

Smethie, W.M., D.W. Chipman, J.H. Swift and K.P. Koltermann 1988: Chlorofluorocarbons in the Arctic Mediterrancan veas: Evidence for formation of bottom water in the Eurasian Basin and deep-water exchange through Fram. Strait. De'ep-Sea Res. 356.3). 347-369.

Wallace. D.W.R.. R.M. Moore. and E.P. Jones. 1987: Ventilation of the Arctic Ocean cold halocline: Rates of diapycnal and ssopycnal transport. oxygen utilization and primary production inferred using chlorofluoromethane distributions. Dép Sea Res.. 34(12), 1957-1979.

Weiss. R.F., J.L. Bullister, R.H. Gammon and M.J. Warner, 1985 Atmospheric chlorofluorocarbons in the deep equatorial Atlantic. Nature.3/4.608-610.

Wisegarver. D.P. and R.H. Gammon, 1988: A new transient tracer; Measured vertical distribution of $\mathrm{CCl}, \mathrm{FCClF}$ ( $\mathrm{F}$ 1 13) in the North Pacitic Subarctic Gyre. Geophy. Res. Letters. 15 (2), $188-14)$

World Occan Circulation Experiment Implementation Plan. 1988: World Meterological Organizatıon. WMO/TD No, 242. $\sqsupset$ 